\title{
Keep on Striving: The Impact of Psychosocial Support on Jordanian Adolescents with Cancer
}

\author{
Ghada Mohammad Abu Shosha \\ Faculty of Nursing, Zarqa University, Zarqa, Jordan \\ Email:ghada_abushosha@yahoo.com,ghada_abushosha@zu.edu.jo
}

Received 26 May 2016; accepted 11 July 2016; published 14 July 2016

Copyright (C) 2016 by author and Scientific Research Publishing Inc.

This work is licensed under the Creative Commons Attribution International License (CC BY). http://creativecommons.org/licenses/by/4.0/

c) (i) Open Access

\begin{abstract}
Having cancer during adolescence stage causes stressors in patients' lives. They are responsible for dealing with many new situations and stressors. Coping with such stressors can be influenced by psychosocial factors. This study aimed to explore the impact of psychosocial support on adolescents with cancer. A qualitative exploratory design was used to understand the experience of psychosocial support from the perspectives of the patients. Twenty adolescents with cancer were selected purposefully from two major cancer treatment centers in Jordan. Semi-structured face-toface interviews were used to obtain the participants' perspectives. Data were analyzed using thematic analysis approach. Findings revealed three major themes: "supportive structure", "precious aspects of psychosocial support", and "cancer could be defeated". Participants expressed their satisfaction with the psychosocial support provided to them. However, they asked for further improvement in hospital facilities, playrooms and leisure activities. In conclusion, having a strong psychosocial support system will help adolescents to cope with cancer. Family, friends, and the surrounding environment are the key elements in installing hope and helping adolescents to go through cancer experience. Nurses are advised to adopt these psychosocial keys in order to create age-related activities that would improve the patients' coping with cancer.
\end{abstract}

\section{Keywords}

Adolescents, Children, Cancer, Nurses, Jordan

\section{Introduction}

Cancer during childhood is a devastating problem worldwide. It is a disease that has the characteristics of 
chronic illnesses and therefore, needs a long term management in all domains of health [1]. Patients face many challenges and stressors resulting from cancer and its treatment [2] [3]. In Jordan, the incidence and the burden of childhood cancer are increasing. There were 207 children in the age group of 0 - 15 years who were newly diagnosed with cancer in Jordan which comprised about (4.4\%) of all registered malignant tumors in the year 2011 compared to 194 (4\%) in the year 2010 [4]. However, the advancement in cancer treatments has yielded higher survival rates so; patients continue to live with lots of concerns related to their physical health, normal development as well as emotional and social problems [5]. To enhance the patients' ability to cope with such an overwhelming disease, a comprehensive psychosocial program is required. Previous studies conducted on patients with cancer have shown that psychosocial support is a pivotal factor that helps patients cope with cancer [6]-[9].

Psychosocial support is considered as those activities which assist children and families to cope with crisis and to strengthen or regain healthy psychosocial development and resilience in the face of challenging circumstances [10]. According to Richter et al. (2006) care and support enable children to have a sense of self-worth and are essential for children to learn, to develop life skills, to participate in the society and to have faith for the future [11]. A study conducted by Woodgate (2006) revealed that supportive relationships helped adolescents with cancer to maintain a sense of being in the world, increased their self-esteem and made them feel loved and cared for [12]. Likewise, Ritchie (2001) reported that the emotional-social support provided to adolescents who had cancer helped them to tolerate living with the cancer experience [13]. Despite the importance of psychosocial support, there is a dearth of evidence in Jordan that demonstrates how adolescents with cancer perceive psychosocial support. In this study, the sources and the impact of psychosocial support from the perspectives of Jordanian adolescents with cancer were explored. This will add to the existing literature of the influence of Arabian culture such as Jordan on the experience of psychosocial support in adolescents with cancer. Subsequently, it helps health care providers to design comprehensive cancer care programs that meet the psychosocial needs of adolescents with cancer.

\section{Materials and Methods}

\subsection{Design}

A descriptive qualitative design was used to explore the impact of psychosocial support on adolescents with cancer. Qualitative research helps researchers to understand the meaning of a phenomenon that people have experienced [14]-[16]. The eligible participants were purposefully selected to participate in this study with the assistance of nurses from two major cancer treatment centers in Amman, the capital of Jordan. The researcher relied on data saturation which is reached when no more new information about the phenomenon under study emerged from the participants to generate further understanding [16] [17].

Participants who met the inclusion criteria were; Jordanian adolescents between the ages of 13 to 17 years old who were physically and psychologically able to participate in the study, had cancer for at least one year, received any type of cancer treatment, knew about their disease before the conduct of the study, and were able to speak and read Arabic fluently. On the contrary, patients with other diseases and patients with altered level of consciousness were excluded from participation.

\subsection{Ethical Considerations}

Ethical approval for conducting this study was secured from the two Jordanian hospitals' ethics committees. Informed consents were obtained from participants and from their parents. Participants and their parents were informed that there was no personal risk involved through participation in this study. In addition, they were informed that participation was totally voluntary and participants had the right to remove any personal information or end the interview at anytime. The use of a digital recording device to record interviews was described to the participants and that they had the right to refuse the tape recording or to delete any saved materials. To guarantee confidentiality; no documentation on the identity of participants and the hospitals were mentioned and each participant was given a code for analyzing and writing up the findings.

\subsection{Data Collection}

Data were collected via in-depth semi-structured, face-to-face interviews using a simple, age-appropriate and understandable Arabic language. The researcher used open-ended questions regarding the sources of psychoso- 
cial support, type of psychosocial support provided to patients, and how that support helped patients with cancer. The interview questions, were derived from the existing literature [9] [12] [13], and were validated by a panel of two expert researchers in qualitative studies. These questions were: 1) Tell me please who provide psychosocial support for you? 2) Are there any other sources of support that help you to adapt with your disease? Tell me please? 3) How do people provide support for you? 4) Can you describe how does support affect your daily life? 5) Are you satisfied with the support you receive? Please describe? 6) What type of support do you think is more beneficial and helps you to continue in your life? 7) Tell me to what extent you feel that the support you receive is successful and make your life better?

Each interview began with getting the participants' permission based upon their understanding of the content of the informed consent form. All efforts were made to establish rapport with all participants to prepare them for interviewing; they were encouraged to talk freely and to tell stories using their own words. This technique allowed the researcher to obtain information about the topic in addition to allowing participants to reply to all questions freely and provide enough illustrations and justifications [16].

All the interviews were conducted by the researcher in a well-ventilated and private room without the presence of parents. Using one interviewer reduce the possibility of bias associated with different investigators. Questions were asked in an appropriate, simple, and understandable way considering the participants' developmental stage and their cognitive capabilities. The mean time of the interviews was about 50 minutes. The interviews were digitally recorded and then transcribed verbatim by the researcher. Transcriptions were re-checked by another researcher. Then, they were translated into English by the researcher and confirmed by a bilingual professional in order to maintain the unique meaning of each interview. The researcher requested participants to attend another meeting in order to validate the study findings. Data collection started from April to the end of August 2014.

\subsection{Data Analysis}

Data analysis was done simultaneously with data collection. Each Transcription was analyzed thematically using the process of thematic analysis suggested by Gibbs [18]. Thematic coding is a method of qualitative data analysis that includes identifying passages of text that are linked by a common idea allowing the researcher to set the text into categories and consequently develop a "framework of thematic ideas" [18]. The researcher firstly looked through the transcriptions as a whole in order to have a comprehensive sense of the data and then read and re-read each transcript very carefully line by line. For each transcript, labeling relevant words, phrases, or sentences pertaining to psychosocial support issues was done. This technique helped the researcher to code the data based on the participants' views. After this, all the created codes were examined and classified into categories or themes that represented a specific and unique idea. The researcher described the connections between these themes considering the integrity of the whole meaning of the data. These themes were mutually exclusive meaning that each code was only placed in one category. Finally, the researcher illustrated the final thematic figure and exhaustively described the themes using quotes taken from the participants' perspectives. Three hundred codes and three major themes emerged from this study.

\subsection{Trustworthiness of Study Findings}

Several strategies were employed in order to enhance rigorous findings. Participants were recruited purposefully and in-depth interviews were conducted with them to obtain rich information about their experiences with psychosocial support [17]. The credibility of the qualitative data generated was also assured by doing member checking whereby the researcher read and discussed the findings of the study with most participants $(\mathrm{N}=17)$. To enhance dependable findings, all transcriptions were double checked for accuracy of translation [14]. In addition, coding of relevant data and examining the relationship between codes were done [14]. To maintain confirmability, the step of cross-checking the data analysis was done by an external researcher. A thick description of the data analysis process was offered so; other investigators could audit this process [14] [17] [19]. Finally, sufficient and comprehensive description of the findings was provided using quotes from the participants' views. This would promote the transferability of this study [17].

\section{Findings}

Twenty adolescents aged between 13 and 17 years participated in this study (mean $=15.15$ ) years. Eleven of 
them were females and nine were males. Most of them have leukemia $(\mathrm{N}=13)$, the others have lymphoma, Wilms' tumor, and osteosarcoma. All participants were oriented about their diseases, all of them were treated with chemotherapy and five of them received radiation. The duration since diagnosis ranged from 14 - 38 months. Table 1 illustrates the demographic characteristics of the twenty participants. Initially, three hundred codes were extracted from the twenty transcriptions; these codes were internally convergent and externally divergent and arranged into ten sub-themes and three major themes. The emerged themes were: supportive structure; precious aspects of psychosocial support; and cancer could be defeated (Table 2). A description of these themes and related sub-themes is provided below.

\subsection{Supportive Structure}

Supportive structure is the first emergent theme in this study. It was addressed in all interviews. All adolescents stated their needs for other people to stay beside them and help them to tolerate the negative effects of cancer and its treatment. Participants were happy and satisfied with the psychosocial support they received from their families, friends and health care providers. In addition, most participants acknowledged the health care environment and services provided to them. This theme comprised of two sub-themes: supportive family and friends and supportive environment.

\subsubsection{Supportive Family and Friends}

All participants described how they greatly relied on their families and friends as they were the closest people to them. Family endures the largest burden in dealing with adolescents during their illness. Getting support from family members was appreciated by Jordanian adolescents as a very valuable factor that helped them to cope positively with their disease and its treatment. A-15-year old female participant reported:

\begin{tabular}{|c|c|c|c|c|}
\hline Patient No. & Gender & Age/year & Diagnosis & Time since diagnosis/month \\
\hline 1 & M & 17 & Leukemia & 14 \\
\hline 2 & $\mathrm{~F}$ & 15 & Lymphoma & 17 \\
\hline 3 & M & 13 & Leukemia & 20 \\
\hline 4 & $\mathrm{~F}$ & 16 & Leukemia & 18 \\
\hline 5 & $\mathrm{~F}$ & 13 & Lymphoma & 17 \\
\hline 6 & $\mathrm{~F}$ & 15 & Leukemia & 14 \\
\hline 7 & M & 16 & Leukemia & 30 \\
\hline 8 & M & 14 & Leukemia & 15 \\
\hline 9 & M & 16 & Lymphoma & 18 \\
\hline 10 & $\mathrm{~F}$ & 17 & Wilms' tumor & 38 \\
\hline 11 & $\mathrm{~F}$ & 17 & Leukemia & 16 \\
\hline 12 & $\mathrm{~F}$ & 14 & Leukemia & 14 \\
\hline 13 & M & 15 & Leukemia & 14 \\
\hline 14 & M & 16 & Osteosarcoma & 35 \\
\hline 15 & M & 13 & Lymphoma & 25 \\
\hline 16 & $\mathrm{~F}$ & 13 & Lymphoma & 19 \\
\hline 17 & $\mathrm{~F}$ & 14 & Leukemia & 16 \\
\hline 18 & $\mathrm{~F}$ & 17 & Leukemia & 31 \\
\hline 19 & M & 15 & Leukemia & 14 \\
\hline 20 & F & 17 & Leukemia & 27 \\
\hline
\end{tabular}

Note: $\mathrm{M}=$ male, $\mathrm{F}=$ female 
Table 2. The emerged themes and sub-themes.

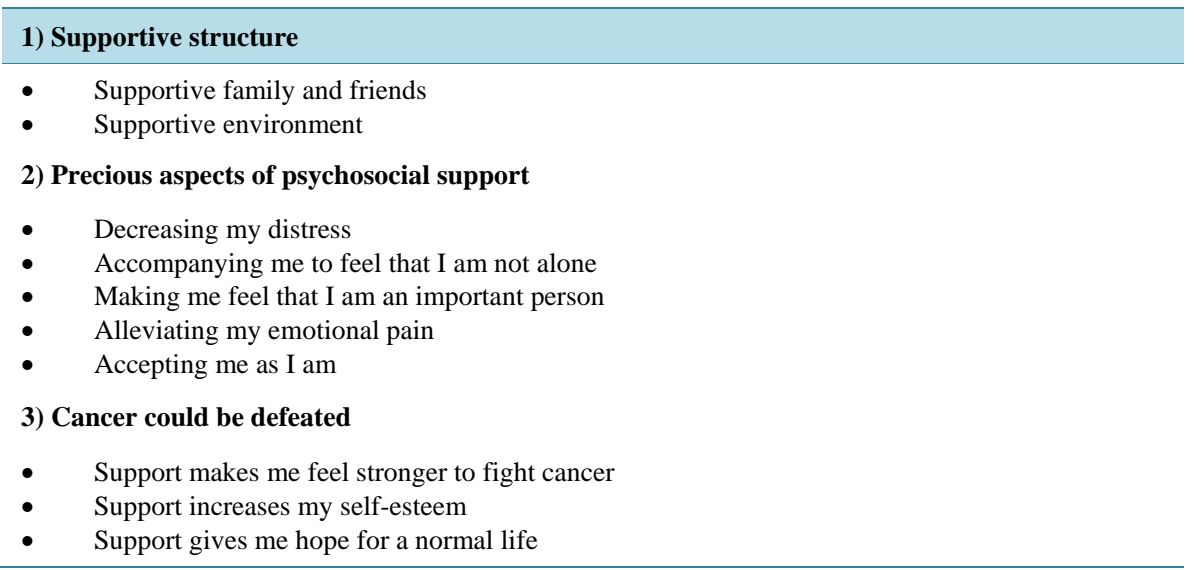

\begin{abstract}
"My mother stays with me all the time and also my father comes every day after work to visit me... they are important to me... they are very caring." (Participant 2).
\end{abstract}

Other participants said:

"My family members love me a lot and bring everything I need and they always bring gifts for me" (Participant 6).

"The presence of family, friends and lovely people around me helped me a lot to deal with my disease. They are the ones who get me out of my bad condition... yes; my life is better due to their presence and support." (Participant 17).

Jordanian adolescents highly valued support obtained from friends who were worried about the patients' conditions. Participants reported the importance of being visited by their friends to discuss age-related issues.

"My friends visit me and tell me about the lessons that I missed in school and they help me a lot." (Participant 16).

"I like my friends to visit me and to go outside together... we spend very lovely time together and talked about our beautiful days in the school... without them, I will be bottlenecked...” (Participant 7).

\title{
3.1.2. Supportive Environment
}

Supportive environment refers to the support that was provided by the health care team as well as the activities and facilities available at the hospitals and acknowledged by participants as helpful. Health care team has an influential role in improving the patients' psychosocial status. Participants in this study described how nurses and physicians tried to help them to cope with their condition. The following quotes represent participants' views:

"Despite the fact that they (referring to the nurses and physicians) are working with cancer patients, they have the spirit of fun and humor, they are trying to help us dealing with our disease...” (Participant 3).

Participants also valued the activities and hospital facilities such as the playroom, educational classroom and participating in parties which were very effective in helping them to cope with the illness.

A-14-year old female participant answered questions about the hospital environment:

"It is perfect; there is a television and they (referring to the hospital staff) bring toys for children ... there is a play room that contains computers." (Participant 12).

Others replied:

"We play outside our rooms, and a girl from the hospital comes in every day to play with us, they (referring to the hospital staff) brought me a laptop" (Participant 1).

"Everything is brilliant in the playroom...there are also laptops... they (referring to the hospital staff) brought one to me in my room." (Participant 4). 
In addition, participants valued the presence of educational facilities such as a classroom, and they asked for further improvement in these educational rooms. One participant stated:

"I go to the educational classroom located in the hospital...we learn mathematics and English, without the educational classroom, I will be behind by two years...I suggest that more rooms should be allocated for education in the hospital and should be equipped with all necessary educational materials." (Participant 8).

Some participants also valued the social activities and parties arranged in the pediatric ward. One participant reported:

"Also, we throw many parties here in the hospital...we bring delicious food and they (referring to the hospital staff) invite musicians and singers, sometimes...they invite story tellers to talk with us...these things make everybody happy and help us to have a good time without thinking about our disease." (Participant 9).

When participants were asked about the most supportive persons to them, participants stated:

"Definitely...my mother is the most supportive person." (Participant 11).

"Surely my parents and my sisters who always try to make me forget about the disease." (Participant 15).

\subsection{Precious Aspects of Psychosocial Support}

All participants reported that psychosocial support contributed to major changes in their lives and empowered them to continue fighting against cancer. Participants provided rich descriptions about the mechanisms put in place by the family members, friends and health care team to support them. These mechanisms were judged by participants as very helpful and supportive and included: decreasing my distress; accompanying me to feel that I am not alone; making me feel that I am an important person; alleviating my emotional pain; and accepting me as I am.

\subsubsection{Decreasing My Distress}

Most participants described the efforts exerted by their families to relieve their tension and stressors associated with cancer and its treatment. One participant reported:

"My family is good and they try to make me happy all the time...they do everything to decrease my tension and distress." (Participant 13).

\subsubsection{Accompanying Me to Feel That I Am Not Alone}

Adolescents showed their happiness as being accompanied by their families. They verbally expressed their satisfaction with being surrounded by their family members. This helped patients to feel more secure and protected. One participant reported that the presence of her family members made her feel that all of them are sharing the disease.

"My family members are always here with me...they give me everything I want and we spend lots of time, playing and laughing...I feel that I am not alone...it feels like all of us are sharing the disease." (Participant 18).

\subsubsection{Making Me Feel That I Am an Important Person}

Participants explicitly verbalized their feelings of being very important persons as a result of psychosocial support provided to them. One participant reported:

"I am really very lucky... I am surrounded by lovely people... my family... my friends... doctors... nurses... I feel that I am really a very important person... everybody tries to make me happy... they all enhance my emotional status." (Participant 19).

\subsubsection{Alleviating My Emotional Pain}

Participants talked extensively about the effective role of their families, friends and health care team in alleviating the emotional pain and sorrow that the patients have because of the deteriorating effects of cancer on them. 
A-17 year old participant described the roles of people in reducing the emotional pain resulting from cancer:

"People around me are trying to reduce my pain...I mean...not only my physical pain, but they also try to reduce the pain in my heart...my emotional pain and stress. Nurses and doctors ask me to think positively, so I will be able to deal with cancer." (Participant 11).

Another participant elaborated:

"Nurses have asked us to look at the bright things in our lives, they said, live your days and love yourselves...This really helps in healing our pain and promoting positive mood, pushing us to be more optimistic for better days." (Participant 3).

\subsubsection{Accepting Me as I Am}

Acceptance of participants by people who surround them means a lot to patients with cancer. Participants in this study strongly appreciated their families and friends who did not change their treatment and feelings towards the patients with cancer. This enhanced a sense of normality in those patients and encouraged them to continue their struggle with cancer in a more hopeful manner. A 15-year old male participant described how his family and friends accepted him despite all the changes in his life:

"My family and friends really care about me... they love me despite the changes in my life... they love me and accept me as I am and deal with me the same way they did before I had the disease... cancer cannot stop them from loving and caring about me." (Participant 19).

Participants also appreciated to be treated as normal by nurses, one participant claimed:

"Nurses are always joking with me and when I buy new clothes; they tell me that they are very beautiful...they deal with me in a normal way." (Participant 5).

\subsection{Cancer Could Be Defeated}

This theme reflects the optimism and the determination to fight the disease among adolescents with cancer. Participants extensively talked about the strength and energy they gained as a result of psychosocial support. They felt that they are well equipped to defeat cancer and to positively continue their lives. This theme was classified as: support makes me feel stronger to fight cancer; support increases my self-esteem; and support gives me hope for a normal life.

\subsubsection{Support Makes Me Feel Stronger to Fight Cancer}

Participants highly valued psychosocial support which increased their ability and strength to go through the cancer journey. Most participants discussed how they became stronger to challenge cancer. The following quotations represent the participants' views regarding psychosocial support:

"My goal in life is to strive against this disease which may affect every baby... child... man... everyone. I will strive and strive and keep on striving. This is my goal in life." (Participant 19).

"Look at my parents! They are trying to do everything to keep me healthy... they tell me that I am very strong because I'm struggling against cancer... this gives me a better meaning to life... so, I promised myself to kill cancer before it will kill me, I am stronger than this bad disease." (Participant 11).

Another participant said:

"When I look into the eyes of my mother... I am drawing from her eyes the strength and power I need... I feel that I am able to continue and challenge my disease." (Participant 2).

\subsubsection{Support Increases My Self-Esteem}

Participants also described how support increased the self-esteem and satisfaction in their lives despite all the changes they had. Participants highly appreciated the presence and words of individuals who encouraged them to sustain and struggle their diseases. This was evident by the following quotes:

"At first, I thought that cancer is really like a prison... it prevents me from doing anything... It kills me 
gradually... but the presence of others beside me helped me a lot... they all built up my self-esteem and my ability to cope, so I am insisting to be free from cancer." (Participant 15).

"Support from lovely persons really means a lot to me; it is the power that helped me to regain my self-esteem and confidence." (Participant 14).

\subsubsection{Support Gives Me Hope for a Normal Life}

Participants extensively described how they gained hope in life as a result of the psychosocial support provided by their families, friends and the health care team. Hope was considered by the participants as an influential factor in maintaining a positive transition through the cancer experience. A 15-year old participant stated:

"Being connected with lovely people helped a lot in promoting my mood... their little words push me forward, install hope in my life and make me more optimistic.” (Participant 13).

\section{Discussion}

The present study explored the impact of psychosocial support on Jordanian adolescents with cancer. The study findings revealed the major sources of psychosocial support as well as the strategies they found to be very effective in helping them to cope with the adversity. The themes that emerged were: supportive structure; precious aspects of psychosocial support; and cancer could be defeated. The study findings asserted that all adolescents need psychosocial support to improve their social and psychological well-being. The same findings were reported by previous studies [8] [9] [20] [21].

In this study, Jordanian adolescents showed their satisfaction with psychosocial support provided to them. This positive attitude may attributed to the social and religious influences of Arabian culture which call for support and social cohesion among people especially in case of illness.

Jordanian participants highly acknowledged the psychosocial support provided by the people surrounding them. Consistent with previous studies, family and friends were the major sources of support for the adolescents and children with cancer [12] [22]. In this study, Jordanian participants valued all strategies done for them by their families and friends to enhance their coping with cancer. These strategies were: Decreasing patients' distress, accompanying them, showing them that they are important, alleviating their emotional pain, and accepting patients as they are. Getting support from family members was in particular a substantial requirement for adapting to stressful feelings. Al Omari and Wynaden (2014) found that Jordanian adolescents need support from their families and peers during their illness to be able to go through the cancer experience [23]. It seems that adolescents with poor relationships with their families and friends are at higher risks for developing psychological problems and maladaptation. Support and acceptance permit patients with cancer to feel normal and to resume their life in a more effective way [24] [25]. Therefore, health care team should enhance Interventions that work through families and friends in order to keep adolescents in supportive and caring environments.

In addition, support provided by the health care team was acknowledged by participants as helpful. Similar studies confirmed the importance of establishing rapport and therapeutic relationships, between patients and their health care providers [22] [26] [27]. Health care providers can help adolescents and children with cancer to cope by providing them with information about cancer and its treatment. This will contribute positively in helping patients to understand their disease and enhance their feeling of control of the disease process [26]-[28]. Indeed, nurses play a key role in encouraging social support as it has been proven that getting support from friends, family, and health care providers is associated with less depression and anxiety [29]. Jordanian adolescents strongly appreciated all the leisure activities and facilities in the hospital as sources of support and entertainment. These include the presence of playrooms and educational classrooms. Grinyer (2007) affirmed that an age-appropriate environment is effective in helping young patients engage in their social activities such as playing music and creating artwork with their peers [30]. Other researchers encouraged the implementation of therapeutic play programs for adolescents with cancer during hospitalization as well as integrating them in leisure activities. These activities can improve the adaptation level and alleviate tension and stress which will lead to better psychosocial adjustment as reported by Enskar et al. and Li et al. [20] [31]. Therefore, the hospital administrators, and the pediatric oncology staff are encouraged to develop age specific cancer units that contribute to less stress and better coping.

Lastly, participants in this study comprehensively described the positive results that psychosocial support had on their inner worlds. In fact, psychosocial support provided the patients with the skills that would help them to 
cope better with the challenges in their daily lives. Jordanian participants declared that they gained strength, self-esteem and hope in normal life which positively changed their thoughts and made them to realize that cancer could be defeated. Hope is considered to be a key factor that contributes to cancer patients' well-being and their tolerance of adversity in life [32]. In addition, hope increases patients' adherence to medical regimen [33]. Nurses and the health team should adopt psychosocial support programs that foster patients' hope.

\section{Conclusion}

This study gives an understanding of the impact of psychosocial support on Jordanian adolescents and children with cancer. The findings reveal that psychosocial support is helpful for adolescents and children to cope with cancer. Family, friends and the surrounding environment are the major factors to install hope and prepare the adolescents to struggle against cancer. Health care providers are invited to integrate psychosocial support interventions into the health care system. In addition, they should enhance social networks between patients and their friends and families when medically able. Further qualitative studies are needed to better understand the impact of psychosocial support on Jordanian adolescents with cancer. In addition, studies to explore the influence of Arabian culture or religion in Jordan on the experience of psychosocial support are recommended. The major limitation of this qualitative study is the lack of generalization. However, the study's findings could be transferable to patients with similar condition.

\section{Declaration of Conflicting of Interests}

The author declares that she has no conflict of interest.

\section{References}

[1] Turnbull-Macdonald, G.C., Baldassarre, F. and Brown, P., et al. (2012) Psychosocialcare for Cancer: A Framework to Guide Practice, and Actionablere Commendations for Ontario. Current Oncology, 19, 209-216. http://dx.doi.org/10.3747/co.19.981

[2] Enskar, K. and Von Essen, L. (2007) Prevalence of Aspects of Distress, Coping, Support and Care among Adolescents/ Young Adults Undergoing and Being off Cancer Treatment. European Journal of Oncology Nursing, 11, 400-408. http://dx.doi.org/10.1016/j.ejon.2007.01.003

[3] Pinquart, M., Frohlich, C. and Silbereisen, R. (2007) Cancer Patients’ Perceptions of Positive and Negative IllnessRelated Changes. Journal of Health Psychology, 12, 907-921. http://dx.doi.org/10.1177/1359105307082454

[4] Jordan Cancer Registry (2011) Cancer Incidence in Jordan. Ministry of Health, 16th Report.

[5] Dalton, S.O., Laursen, T.M., Ross, L., Mortensen, P.B. and Johansen, C. (2009) Risk for Hospitalization with Depression after a Cancer Diagnosis: A Nationwide, Population-Based Study of Cancer Patients in Denmark from 1973 to 2003. Journal of Clinical Oncology, 27, 1440-1445. http://dx.doi.org/10.1200/JCO.2008.20.5526

[6] Ramini, S., Brown, R., and Buckner, E. (2008) Embracing Changes: Adaptation by Adolescents with Cancer. Pediatric Nursing, 34, 72-79.

[7] Shama, W. and Lucchetta, S. (2007) Psychosocial Issues of the Adolescent Cancer Patient and the Development of the Teenage Outreach Program (TOP). Journal of Psychosocial Oncology, 25, 99-112. http://dx.doi.org/10.1300/J077v25n03_06

[8] Freeman, K., O’Dell, C. and Meola, C. (2003) Childhood Brain Tumors: Children’s and Siblings' Concerns Regarding the Diagnosis and Phase of Illness. Journal of Pediatric Oncology Nursing, 20, 133-140. http://dx.doi.org/10.1053/jpon.2003.74

[9] Hokkanen, H., Eriksson, E., Ahonen, O. and Salantera, S. (2004) Adolescents with Cancer Experience of Life and How It Could Be Made Easier. Cancer Nursing, 27, 325-335. http://dx.doi.org/10.1097/00002820-200407000-00010

[10] UNICEF (2005) Programming for Psychosocial Support, Frequently Asked Questions. https://www.google.jo/?gfe_rd=cr\&ei=l5xrV-n5Gcis8weD-7b4BQ\&gws_rd=ssl\#q=UNICEF+(2005)+Programming $+f$ or+Psychosocial+Support\%2C+Frequently+Asked+Questions

[11] Richter, L., Foster, G. and Herr, L. (2006) Where the Heart Is, Meeting the Psychosocial Needs of Young Children in the Context of HIV and AIDS. http://www.unicef.org/violencestudy/pdf/Where\%20the\%20Heart\%20Is.pdf

[12] Woodgate, R. (2006) The Importance of Being There: Perspectives of Social Support by Adolescents with Cancer. Journal of Pediatric Oncology, 23, 122-134. http://dx.doi.org/10.1177/1043454206287396

[13] Ritchie, M. (2001) Sources of Emotional Support for Adolescents with Cancer. Journal of Pediatric Oncology Nursing, 


\section{8, 105-110. http://dx.doi.org/10.1177/104345420101800303}

[14] Creswell, J. (2009) Research Design; Qualitative, Quantitative, and Mixed Methods Approaches. 3rd Edition, SAGE Publication Ltd., Los Angeles.

[15] Merriam, S. (2009) Qualitative Research: A Guide to Design and Implementation. Jossey-Bass, San Francisco.

[16] Polit, D.F. and Beck, C.T. (2008) Nursing Research: Generating and Assessing Evidence for Nursing Practice. Lippincott, Williams and Wilkins, Philadelphia.

[17] Speziale, H.J. and Carpenter, D.R. (2007) Qualitative Research in Nursing: Advancing the Humanistic Imperative. 4th Edition, Lippincott, Williams and Wilkins, Philadelphia.

[18] Gibbs, G.R. (2007) Thematic Coding and Categorizing, Analyzing Qualitative Data. SAGE Publications Ltd., London. http://dx.doi.org/10.4135/9781849208574

[19] Lewis, J. and Ritchie, J. (2003) Generalizing from Qualitative Research. In: Ritchie, J. and Lewis, J., Eds., Qualitative Research Practice: A Guide for Social Science Students and Researchers, SAGE Publications, London, 263-286.

[20] Enskar, K., Carlson, M. and Hamrin, E. (1997) Symptom Distress and Life Situation in Adolescents with Cancer. Cancer Nursing, 20, 23-33. http://dx.doi.org/10.1097/00002820-199702000-00004

[21] Stegenga, K. and Ward-Smith, P. (2009) On Receiving the Diagnosis of Cancer: The Adolescent Perspective. Journal of Pediatric Oncology Nursing, 26, 75-80. http://dx.doi.org/10.1177/1043454208328767

[22] Kyngas, H., Mikkonen, R., Nousiainen, E., Rytilahti, M., Seppanen, P., Vaattovaara, R. and Jamsa, T. (2001) Coping with the Onset of Cancer: Coping Strategies and Resources of Young People with Cancer. European Journal of Cancer Care, 10, 6-11. http://dx.doi.org/10.1046/j.1365-2354.2001.00243.x

[23] Al Omari, O. and Wynaden, D. (2014) The Psychosocial Experience of Adolescents with Haemaological Malignancies in Jordan: An Interpretive Phenomenological Analysis Study. The Scientific World Journal, 2014, Article ID: 274036. http://dx.doi.org/10.1155/2014/274036

[24] Larouche, S. and Chin-Peuckert, L. (2006) Changes in Body Image Experienced by Adolescents with Cancer. Journal of Pediatric Oncology Nursing, 23, 200-209. http://dx.doi.org/10.1177/1043454206289756

[25] Williamson, H., Harcourt, D., Halliwell, E., Frith, H. and Wallace, M. (2010) Adolescents' and Parents' Experiences of Managing the Psychosocial Impact of Appearance Change during Cancer Treatment. Journal of Pediatric Oncology Nursing, 27, 168-175. http://dx.doi.org/10.1177/1043454209357923

[26] Hedstrom, M., Skolin, I. and Von-Essen, L. (2004) Distressing and Positive Experiences and Important Aspects of Care for Adolescents Treated for Cancer: Adolescent and Nurse Perceptions. European Journal of Oncology Nursing, 8, 6-17. http://dx.doi.org/10.1016/j.ejon.2003.09.001

[27] Wallace, M., Harcourt, D., Rumsey, N. and Foot, A. (2007) Managing Appearance Changes Resulting from Cancer Treatment: Resilience in Adolescent Females. Psychoncology, 16, 1019-1027. http://dx.doi.org/10.1002/pon.1176

[28] Decker, C., Phillips, C. and Haase, J. (2004) Information Needs of Adolescents with Cancer. Journal of Pediatric Oncology Nursing, 21, 327-334. http://dx.doi.org/10.1177/1043454204269606

[29] Corey, A., Haase, J., Azzouz, F. and Monahan, P. (2008) Social Support and Symptom of Distress in Adolescents and Young Adults with Cancer. Journal of Pediatric Oncology Nursing, 25, 275-284. http://dx.doi.org/10.1177/1043454208321117

[30] Grinyer, A. (2007) The Biographical Impact of Teenage and Adolescent Cancer. Chronic Illness, 3, 265-277. http://dx.doi.org/10.1177/1742395307085335

[31] Li, H., Chung, O. and Chiu, S. (2010) The Impact of Cancer on Children's Physical, Emotional, and Psychosocial Well-Being. Cancer Nursing, 33, 47-54. http://dx.doi.org/10.1097/NCC.0b013e3181aaf0fa

[32] Eliott, J.A. and Olver, I.N. (2009) Hope, Life, and Death: A Qualitative Analysis of Dying Cancer Patients’ Talk about Hope. Death Studies, 33, 609-638. http://dx.doi.org/10.1080/07481180903011982

[33] Gordon, E.J. and Daugherty, C.K. (2003) "Hitting You over the Head”: Oncologists’ Disclosure of Prognosis to Advanced Cancer Patients. Bioethics, 17, 142-168. http://dx.doi.org/10.1111/1467-8519.00330 


\section{Submit or recommend next manuscript to SCIRP and we will provide best service for you:}

Accepting pre-submission inquiries through Email, Facebook, LinkedIn, Twitter, etc.

A wide selection of journals (inclusive of 9 subjects, more than 200 journals)

Providing 24-hour high-quality service

User-friendly online submission system

Fair and swift peer-review system

Efficient typesetting and proofreading procedure

Display of the result of downloads and visits, as well as the number of cited articles

Maximum dissemination of your research work

Submit your manuscript at: http://papersubmission.scirp.org/ 